\title{
A Modified Pain Therapy for Thoracic Compression Fracture in the Elderly: Cooled Radiofrequency Ablation at Thoracic Facet Joints
}

\author{
Shang Yi Lee, MD, Yi-Ying Chiang, MD, Yu-Chen Liu, MD, Kuen-Bao Chen, MD, PhD, and \\ Yeong-Ray Wen, MD, PhD
}

We reported an alternative therapy for 2 cases respectively with acute and old thoracic compression fracture and persistent back pain. A 94-yearold woman who had multiple comorbidities suffered from severe pain that was caused by an acute thoracic spine compression fracture. The other patient was an 89-year-old man with an old thoracic compression fracture for 2 years. Neither of them could have satisfactory pain relief by the conservative treatments. Surgical intervention was also not considered. Cooled radiofrequency ablation was applied to both patients' thoracic facet joints. The 2 patients' back pain improved considerably after the ablation. Cooled radiofrequency ablation over thoracic facet joints could be a pain management alternative for relieving thoracic compression fracture-related pain.

Key words: Compression fracture, thoracic vertebra, cooled radiofrequency denervation, facet joint, comorbidity
Thoracolumbar spine compression fracture is one of the most common devastating pain sources in older patients. Although vertebroplasty is a standard treatment for spinal compression fracture $(1,2)$, its efficacy remains controversial by recent studies $(3,4)$. The uses of local anesthetics, placebo effects from the patients' expectations, and natural healing process of the fracture all account for the controversial conclusions (3). In addition, the elderly may have various major comorbidities, which increase anesthetic and surgical risks and limit the possibility of surgery. Chronic pain in these patients deteriorates their functionality, physical condition, and quality of life. In this report, 2 cases having severe pain from acute and old compression fractures were successfully treated with cooled radiofrequency ablation.

\section{CASE DESCRIPTION}

\section{Case 1}

A 94-year-old woman with coronary artery disease,

From : Pain Management and Research Center, Department of Anesthesiology, China Medical University Hospital, Taichung, Taiwan

Author for correspondence: Yeong-Ray Wen, MD, PhD Address: China Medical University Hospital, Taichung, Taiwan E-mail: yray.wen@gmail.com atrial fibrillation, valvular heart disease, heart failure, stroke with hemiparesis, carotid artery stenosis, and medicated with an anticoagulant had presented with low back pain lasting for several years. A new onset of pain with a Numeric Rating Scale (NRS) $=8$ (from 0 to $10 ; 0$ represents no pain and 10 represents intolerable pain) at the mid-back had been noted for several weeks. Radiographs revealed decreased height of the T12 vertebral body. Magnetic resonance imaging (MRI) indicated an acute T12 compression fracture on sagittal T2 short tau inversion recovery (STIR) images (Fig. 1), in addition to the previous existence of osteoarthritis of the L3-S1 facet joints and foraminal stenosis. Acute pain from the T12 compression fracture superimposed on chronic lumbar pain was suspected.

The patient initially received conservative medical treatment with Ultracet (Janssen Pharmaceuticals, Inc., Raritan, NJ), rehabilitation, and brace protection without consideration of surgery or interventional pain management due to multiple comorbidities. These treatments did not alleviate her pain. Unfortunately, she was prescribed tramadol $100 \mathrm{mg} 3$ times per day for the severe back pain and developed unconsciousness. The patient was then sent to the emergency department and hospitalized. 
After conscious recovery, the patient felt severe broad back pain again. She could only lie on the bed and lacked the ability to sit long enough for a meal. Orthopedics was consulted but the surgical intervention was not suggested due to high risks from multiple comorbidities. Therefore, the pain doctor was consulted and diagnostic block at bilateral T10/T11

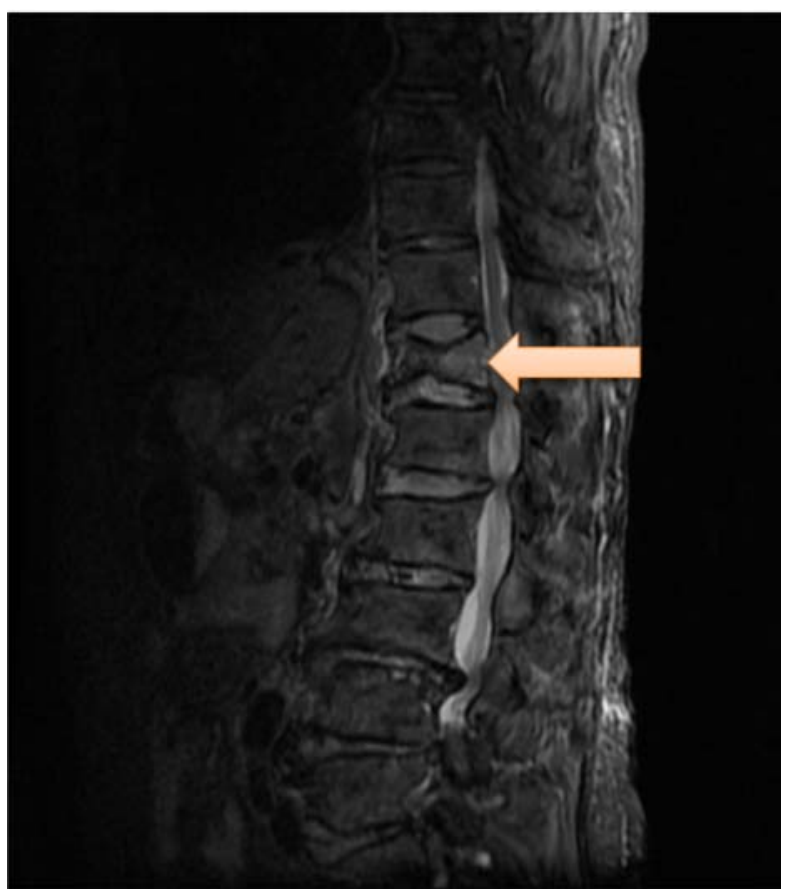

Fig. 1. An MRI of case 1 indicated an acute T12 compression fracture at sagittal T2 STIR images.
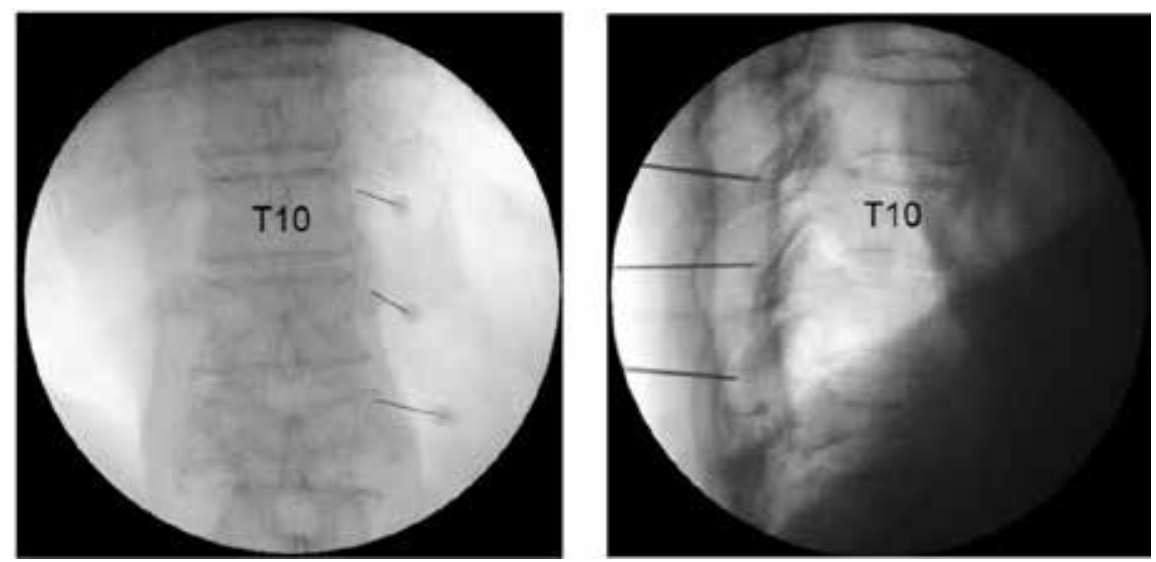

Fig. 2. Needles for cooled radiofrequency ablation were inserted to the right T10, $\mathrm{T} 11$, and $\mathrm{T} 12$ transverse processes close to the medial branches. and T11/12 facet joints under ultrasound guidance was conducted. The block effect was encouraging. The patient could sit longer than one hour after the block and the pain score was NRS $=3$. Therefore, thoracic facet joint ablation was suggested, and her family agreed to the intervention.

The patient received cooled radiofrequency (Coolief, Avanos, Alpharetta, Georgia) ablation at bilateral T9, T10, T11, and T12 medial branches (Fig. 2). After the ablation, her back pain improved with the pain score of NRS $=3$, and her family was satisfied with her prolonged sitting duration on the bed. The analgesics could be reduced to only etoricoxib one tablet per day without opioids. Her back pain had not recurred after a 2-month follow-up. Unfortunately, the patient died of an aspiration event 2 months later.

\section{Case 2}

An 89-year-old man with a history of chronic obstructive pulmonary disease had complained of intermittent back pain with NRS $=7$ over the mid-thoracic level and the right lateral lower chest wall for the past 2 years. Physical examination showed kyphosis, local tenderness over the right paraspinal muscle, and regional knocking pain from the middle to lower $T$ spine. MRI identified an old compression fracture at T11 (Fig. 3) as compared with the radiographic images 2 years ago. The patient had received medication with Ultracet, one tablet 3-4 times per day, for the past 2 years and the pain still progressed. Under the suspicion of thoracic facet-related pain, diagnostic blocks were performed at the right $\mathrm{T} 9 / 10, \mathrm{~T} 10 / 11$, and T11/12 facet joints with $>50 \%$ pain reduction locally and residual soreness at higher levels. Therefore, cooled radiofrequency ablation was suggested.

Cooled radiofrequency ablation was conducted at the right T7, T8, T9, T10, and T11 medial branches (Fig. 4) and back pain was reduced to NRS $<3$ a few days after the procedure. Mild pain and soreness over the right 
paraspinal and subscapular regions at mid-thoracic levels were noted. Subsequent trigger point injections at the T-spine erector muscles and latissimus dorsi muscle were performed weekly for 4 weeks, and the pain was further reduced to NRS $=1$. The patient continued Ultracet 0-1 tablet per day and back pain did not recur after a 3-month follow-up.

\section{PROCEDURE}

We performed cooled radiofrequency ablation for both cases in the operation room. The patient was placed in the prone position and received intravenous conscious sedation. Following local disinfection and aseptic draping, skin anesthesia was performed with $1 \mathrm{~mL}$ of $2 \%$ lidocaine, and the 17 gauge radiofrequency needles were inserted to the target sites (superolateral regions of the transverse processes at levels above T11 and the lateral surface of superior articular process at T12 level) under fluoroscopy guidance. After electrical stimulation to confirm no motor response, $1-2 \mathrm{~mL}$ of $2 \%$ lidocaine was injected followed by radiofrequency ablation with $60^{\circ} \mathrm{C}$ for 150 seconds at each nerve. Postprocedural chest radiograph was performed to rule-out pneumothorax. There was also no complication after follow-up.

\section{DISCUSSION}

The treatment of compression fracture includes conservative oral analgesics, bracing, physical therapy, and vertebral augmentation procedures $(1,2)$. Vertebroplasty, in most cases, could be a better and faster medical choice to alleviate acute compression fracture-induced pain $(5,6)$, however, recent evidences may not support this $(3,4)$. In addition, despite multiple treatment modalities, the pain may not be alleviated by these managements.

Bogduk et al (7) postulated a biomechani- cal model for posterior elemental pain in patients with compression fracture. According to this theory, the pain source in these patients could be illustrated as Fig. 5, and the medial branch nerve ablation becomes an alternative treatment for relieving pain with compression fracture $(7,8)$.

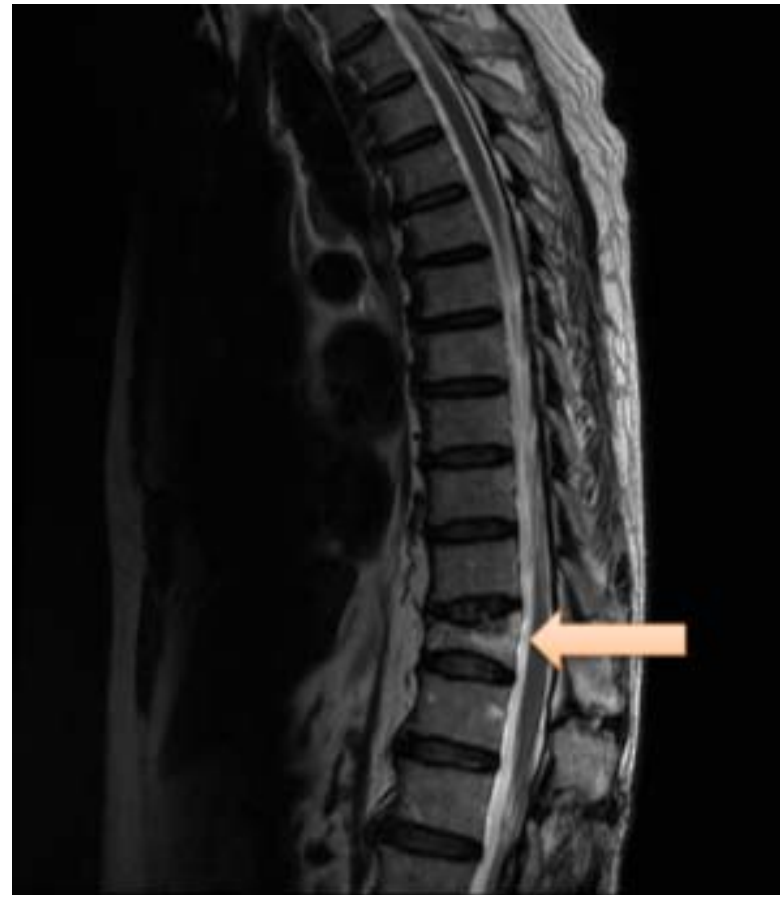

Fig. 3. An MRI of case 2 revealed an old T11 compression fracture at sagittal T2 fast recovery fast, spin echo images.
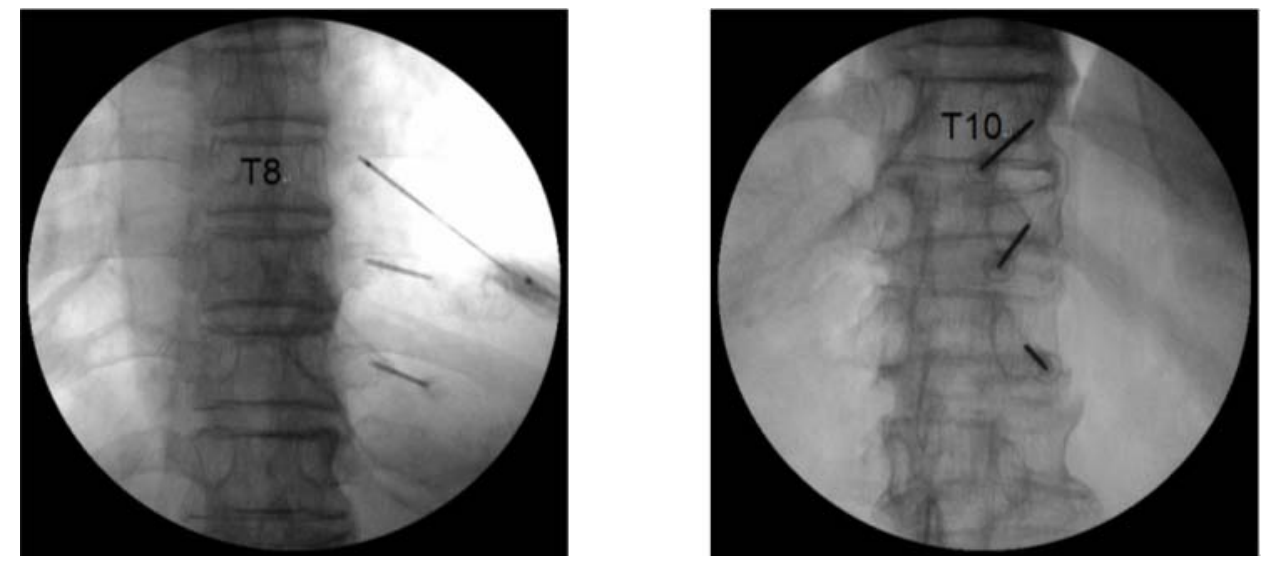

Fig. 4. Needles for cooled radiofrequency ablation at multiple levels. Left panel: needle tips at superolateral regions of right T8, T9, T10 transverse processes (anteroposterior view). Right panel: tips at the T10, T11 transverse processes, and at the lateral surface of T11/12 facet joint (oblique view). 


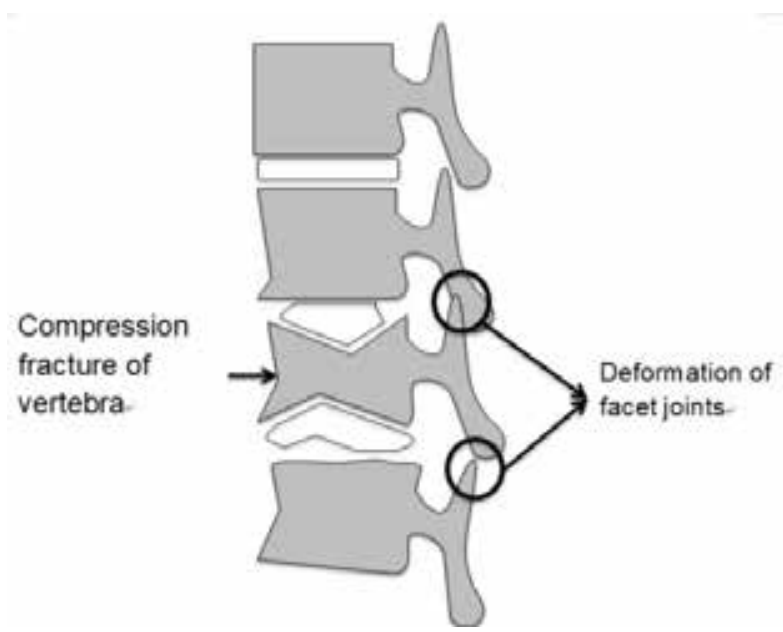

Fig. 5. According to the theory of posterior elemental pain of compression fracture from Bogduk et al (7), the pain source in our patients could be illustrated as the figure.

The thoracic medial branch nerves course variably, such as running along the lateral end of the superior border of the transverse process then entering the muscle compartment of the back, or embracing the base of the superior articulate process, or situated in the soft tissue between the transverse processes $(9,10)$. Because of high anatomic variability, conventional radiofrequency ablation needs to be applied at multiple points along possible nerve courses to increase the success rate.

For pain management, cooled radiofrequency ablation has been chosen mostly for treating sacroiliac joint pain and showed a better result than conventional radiofrequency ablation in light of its large ablation size (11). Other case series reported applications in treating lumbar facet joint syndrome (12) and discogenic low back pain (13). A cadaveric study revealed using cooled radiofrequency ablation may be effective for treating thoracic facet joint pain (14).

However, the debate between the conventional and cooled radiofrequency ablation still exists (15).
Cooled radiofrequency ablation leads to a spherical rather than an elliptical shaped lesion and creates a much larger burning area compared with conventional radiofrequency ablation. This advantage makes cooled radiofrequency a better choice of treatment at particular targets with anatomically high variations of nerve distribution, such as the thoracic facet joint and sacroiliac joint. Usually, this technique is safe and short, and can reduce radiation exposure theoretically (15). However, the risk of burn injury was reported (16), and there is still lack of large and long-term randomized-controlled studies to prove its cost-effectiveness.

In the first case who had an acute compression fracture, vertebroplasty could cause relatively high surgical and anesthetic risks evaluated by the orthopedics and her family. The use of opioids led to severe conscious deterioration. As a result, adequate pain control to restore basic life quality became a humble desire of the patient and her family. In the second case, the pain area was wide and may comprise both old compression fracture and chronic myofascial pain. Diagnostic block became important to map pain sources. Accordingly, we decided a broad radiofrequency ablation at the medial branches of more levels than the nerves of the fractured segment to avoid another ablation treatment for insufficient effect.

To the best of our knowledge, this is the first report using cooled radiofrequency for thoracic medial branch ablation in patients with acute or old compression fracture. We present our experiences for future choice of treating such complex pain condition in older patients. Further systemic investigation of this modality should be initiated.

\section{CONCLUSIONS}

Cooled radiofrequency ablation at the medial branches to facet joints adjacent to the fracture spine level could be a safe and effective pain-relieving alternative for the elder patients. 


\section{REFERENCES}

1. Goldstein CL, Chutkan NB, Choma TJ, Orr RD. Management of the elderly with vertebral compression fractures. Neurosurgery 2015; 77(Suppl 4):S33-S45.

2. Genev IK, Tobin MK, Zaidi SP, Khan SR, Amirouche FML, Mehta Al. Spinal compression fracture management: A review of current treatment strategies and possible future avenues. Global Spine ] 2017; 7:71-82.

3. Firanescu CE, de Vries J, Lodder P, Venmans A, Schoemaker MC, Smeet AJ, Donga E, Juttmann JR, Klazen CAH, Elgersma $\mathrm{OEH}$, Jansen FH, Tielbeek AV, Boukrab I, Schonenberg K, van Rooij WJJ, Hirsch JA, Lohle PNM. Vertebroplasty versus sham procedure for painful acute osteoporotic vertebral compression fractures (VERTOS IV): Randomized sham controlled clinical trial. BMJ 2018; 361:k1551.

4. Buchbinder R, Johnston RV, Rischin KJ, Homik J, Jones CA, Golmohammadi K, Kallmes DF. Percutaneous vertebroplasty for osteoporotic vertebral compression fracture. Cochrane Database Syst Rev 2018; 4:CD006349.

5. Klazen CA, Lohle PN, de Vries J, Jansen FH, Tielbeek AV, Blonk MC, Venmans A, van Rooij WJ, Schoemaker MC, Juttmann JR, Lo TH, Verhaar HJ, van der Graaf Y, van Everdingen KJ, Muller AF, Elgersma OE, Halkema DR, Fransen H, Janssens X, Buskens E, Mali WP. Vertebroplasty versus conservative treatment in acute osteoporotic vertebral compression fractures (Vertos II): An open-label randomized trial. Lancet 2010; 376:1085-1092.

6. Clark W, Bird P, Gonski P, Diamond TH, Smerdely P, McNeil HP, Schlaphoff G, Bryant C, Barnes E, Gebski V. Safety and efficacy of vertebroplasty for acute painful osteoporotic fractures (VAPOUR): A multicentre, randomised, double-blind, placebo controlled trial. Lancet 2016; 388:1408-1416.

7. Bogduk N, MacVicar J, Borowczyk J. The pain of vertebral compression fractures can arise in the posterior elements. Pain Med 2010; 11:1666-1673.
8. Solberg J, Copenhaver D, Fishman SM. Medial branch nerve block and ablation as a novel approach to pain related to vertebral compression fracture. Curr Opin Anaesthesiol 2016; 29:596599.

9. Chua WH, Bogduk N. The surgical anatomy of thoracic facet denervation. Acta Neurochir 1995; 136:140-144.

10. International Spine Intervention Society, Standards Committee. Thoracic medial branch blocks. In: Bogduk N (ed). Practice Guidelines for Spinal Diagnostic and Treatment Procedures. San Francisco, CA, International Spine Intervention Society, 2004: pp. 330-347.

11. Hansen H, Manchikanti L, Simopoulos TT, Christo PJ, Gupta S, Smith HS, Hameed H, Cohen SP. A systematic evaluation of the therapeutic effectiveness of sacroiliac joint interventions. Pain Physician 2012; 15:E247-E278.

12. McCormick ZL, Walker J, Marshall B, McCarthy R, Walega DR. A novel modality for facet joint denervation: Cooled radiofrequency ablation for lumbar facet syndrome. A case series. Phys Med Rehabil Int 2014; 1:5.

13. Desai MJ, Kapural L, Petersohn JD, Vallejo R, Menzies R, Creamer M, Gofeld M. Radiofrequency intradiscal biacuplasty for treatment of discogenic lower back pain: A 12-month followup. Pain Med 2015; 16:425-431.

14. Mekhail N, Cheng J. Temperature mapping of cooled radiofrequency lesion of human cadaver thoracic facet medial branches. Clin J Pain 2010; 27:56-61.

15. Bajaj PS, Napolitano J, Wang W, Cheng J, Singh JR. Cooled versus conventional thermal radiofrequency neurotomy for the treatment of lumbar facet-mediated pain. PMR 2015; 7:10951101.

16. Walega D, Roussis C. Third-degree burn from cooled radiofrequency ablation of medial branch nerves for treatment of thoracic facet syndrome. Pain Pract 2014; 14:e154-e158. 
